\title{
Insulin resistance and cortisol metabolism. Reply to Kerstens MN, Dullaart RPF [letter]
}

\author{
C. D. Byrne • S. H. Wild • D. I. Phillips • H. Holt
}

Received: 31 May 2007 / Accepted: 1 June 2007 / Published online: 13 July 2007

(C) Springer-Verlag 2007

Keywords Cortisol - Glucocorticoid receptor .

Glucocorticoids · Insulin resistance · Insulin sensitivity ·

Non-alcoholic fatty liver disease $\cdot$ Obesity $\cdot$ Salt resistance

\section{Abbreviations \\ HOMA-IR homeostasis model assessment of insulin resistance}

To the Editor: We thank M. N. Kerstens and R. P. F. Dullaart for their interest in our paper [1]. Our results show that there was an inverse relationship between cortisol clearance from the plasma and whole-body insulin sensitivity as measured by the hyperinsulinaemic-euglycaemic clamp in middle-aged men (mean age 53.0 years, mean

\section{D. Byrne $(\bowtie)$}

Endocrinology and Metabolism, The Institute of Developmental Sciences (IDS Building), University of Southampton, MP 887 Southampton General Hospital Tremona Road,

Southampton SO16 6YD, UK

e-mail: cdtb@soton.ac.uk

URL: http://www.metabolicsyndrome.org.uk

URL: http://www.som.soton.ac.uk/research/dohad/

S. H. Wild

Public Health Sciences, University of Edinburgh,

Edinburgh, UK

\section{I. Phillips}

MRC Environmental Epidemiology Unit, DOHaD Division, University of Southampton,

Southampton, UK

H. Holt

Endocrinology and Metabolism, DOHaD Division,

University of Southampton,

Southampton, UK
BMI $32.0 \mathrm{~kg} / \mathrm{m}^{2}$ ) [2]. Importantly, we show that this relationship was independent of potential confounding factors such as body fat and fatty liver. These findings were contrary to our expectations and we agree that it is now crucial to undertake careful kinetic studies to study cortisol production (and excretion) in more detail to determine specifically whether cortisol production is increased. We agree that by measuring urinary free cortisol we have only assessed a small fraction of all urinary cortisol metabolites. It is possible that there is increased renal loss of cortisol with insulin resistance that we have not detected.

We appreciate that we have not assessed salt resistance in our subjects, but there is no consensus as to whether salt loading worsens, improves, or has no effect on insulin sensitivity [3-6]. Kerstens et al. [7] studied cortisol metabolism, insulin sensitivity (according to homeostasis model assessment of insulin resistance [HOMA-IR]) and renal haemodynamics in 19 salt-resistant and nine salt-sensitive normotensive subjects after a low- and high-salt diet. Although in their letter [1] Kerstens and Dullaart pass comment on their observation of a significant positive relationship between percentage change in HOMA-IR and percentage change in plasma cortisol during salt loading [7] (at variance with our findings), it should be noted that in the same study [7] they also describe a significant inverse relationship between percentage change in HOMA-IR and percentage change in the sum of urinary metabolites (in keeping with our findings). Moreover, the authors studied young men and women (mean age 24 years) who were lean (mean BMI $22 \mathrm{~kg} / \mathrm{m}^{2}$ ). In contrast, we studied middle-aged men only and our volunteers were predominantly obese. The relationships between cortisol metabolism and insulin sensitivity may differ in insulin-resistant, obese individuals 
and insulin-sensitive, thin individuals. It is also plausible that ageing affects the relationship between cortisol metabolism and insulin sensitivity.

There are many factors that may potentially confound a relationship between aspects of cortisol metabolism and insulin sensitivity, such as body fat percentage, fat distribution or fatty liver status. We have adjusted for these confounders in the regression analyses. Kerstens et al. [7] did not comment on confounding by these or other factors.

We have recently shown that in fasting plasma samples (collected at 09:00 hours), cortisol was decreased in South Asians with features of the metabolic syndrome compared with white northern Europeans living in the UK, despite both groups having similar BMIs (BMI $25.6 \mathrm{~kg} / \mathrm{m}^{2}$ for both groups) [8]. This finding is in keeping with the original description by Bjorntorp [9] of a flat, rigid day curve for plasma cortisol, with poor feedback control in insulinresistant individuals with abdominal obesity, increased leptin levels, hyperglycaemia, dyslipidaemia and hypertension. Moreover, there is increased skeletal muscle glucocorticoid receptor expression with obesity and features of the metabolic syndrome $[10,11]$. Thus, in insulin-resistant, obese individuals it is plausible that the flat, rigid day curve with decreased morning cortisol concentrations may represent increased tissue cortisol clearance. If there is increased tissue cortisol uptake and increased tissue glucocorticoid receptor expression in key insulin-sensitive tissues, then it is possible that a Cushing's syndrome phenotype or metabolic syndrome phenotype could result.

In conclusion, we concur with Kerstens and Dullart that more research is needed to carefully delineate cortisol biosynthesis and clearance pathways. We consider that these studies are needed, particularly in relation to insulin sensitivity, non-alcoholic fatty liver disease and the metabolic syndrome phenotype in different ethnic groups.
Duality of interest The authors declare that there is no duality of interest associated with this manuscript.

\section{References}

1. Kerstens MN, Dullart RPF (2007) Comment on: Holt HB, Wild SH, Postle AD et al (2007) Cortisol clearance and associations with insulin sensitivity, body fat and fatty liver in middle-aged men. Diabetologia 50:1024-1032. Diabetologia DOI 10.1007/s00125007-0736-7

2. Holt HB, Wild SH, Postle AD et al (2007) Cortisol clearance and associations with insulin sensitivity, body fat and fatty liver in middle-aged men. Diabetologia 50:1024-1032

3. Foo M, Denver AE, Coppack SW, Yudkin JS (1998) Effect of salt-loading on blood pressure, insulin sensitivity and limb blood flow in normal subjects. Clin Sci (Lond) 95:157-164

4. Giner V, Coca A, de la Sierra A (2001) Increased insulin resistance in salt sensitive essential hypertension. J Hum Hypertens $15: 481-485$

5. Melander O, Groop L, Hulthen UL (2000) Effect of salt on insulin sensitivity differs according to gender and degree of salt sensitivity. Hypertension 35:827-831

6. Townsend RR, Kapoor S, McFadden CB (2007) Salt intake and insulin sensitivity in healthy human volunteers. Clin Sci (Lond) (DOI 10.1042/CS20060361 [Epub ahead of print])

7. Kerstens MN, van der Kleij FG, Boonstra AH, Sluiter WJ, Koerts J, Navis G et al (2003) Salt loading affects cortisol metabolism in normotensive subjects: relationships with salt sensitivity. J Clin Endocrinol Metab 88:4180-4185

8. Reynolds RM, Fischbacher C, Bhopal R et al (2006) Differences in cortisol concentrations in South Asian and European men living in the United Kingdom. Clin Endocrinol (Oxf) 64:530-534

9. Bjorntorp P, Holm G, Rosmond R (1999) Hypothalamic arousal, insulin resistance and type 2 diabetes mellitus. Diabet Med 16: 373-383

10. Whorwood CB, Donovan SJ, Flanagan D, Phillips DI, Byrne CD (2002) Increased glucocorticoid receptor expression in human skeletal muscle cells may contribute to the pathogenesis of the metabolic syndrome. Diabetes 51:1066-1075

11. Reynolds RM, Chapman KE, Seckl JR, Walker BR, McKeigue PM, Lithell HO (2002) Skeletal muscle glucocorticoid receptor density and insulin resistance. JAMA 287:2505-2506 